\title{
UNAS ORDENANZAS DE LA SIERRA DE CAZORLA (1552)
}

\author{
María del Mar García Guzmán \\ Universidad de Cádiz
}

\section{RESUMEN:}

El concejo de Cazorla promulgó, a mediados del siglo XVI, unas ordenanzas por las que se regulaba la explotación de su Sierra y en general de sus términos. La nueva normativa tenía como objetivo conservar su riqueza forestal por lo que se prohibieron algunas costumbres mantenidas a lo largo de los siglos precedentes por los vecinos de Cazorla y La Iruela. PALABRAS CLAVE: Cazorla, ordenanzas municipales, bosque.

\section{ABSTRACT:}

The council of Cazorla promulgated, in the middle of century XVI, decrees by which the operation of its Mountain range in general of its terms is regulated. The new norm had as objective to conserve their forest wealth reason why some customs maintained throughout the preceding centuries by neighbors of Cazorla and the Iruela were prohibited. KEY WORDS: Cazorla, by-laws, woodland. 
En las Ordenanzas de Cazorla de 1552 se expone en primer lugar, el motivo que llevó a las autoridades municipales a promulgar una normativa destinada a conservar la riqueza natural de la Sierra de Cazorla: "por quanto por esecutoria y provision real de su majestad, atenta la utilidad de los dichos montes y la necesidad que dellos ay y que sean conserbados, esta mandado que nyngun vecino desta villa ny de fuera parte pueda arronper, arar, ny panyficar en la dicha syerra del tienpo contenido en la dicha esecutoria..."1. Pero la nueva reglamentación introducía importantes novedades en el aprovechamiento de los términos comunes de Cazorla y La Iruela y modificaba, en gran medida, la costumbre mantenida a lo largo de la Edad Media.

La existencia de un término compartido entre varias villas es una de las características de la organización territorial del Adelantamiento. A finales del siglo XIII ${ }^{2}$, el señorío contaba con dos villas, Cazorla e Iznatoraf, y cada una tenía asignado un alfoz. En el transcurso de las centurias siguientes, algunas de las aldeas se convirtieron en villas, pero en ningún caso los arzobispos de Toledo les concedieron un término propio, sino que se mantenía compartido con la antigua villa principal. De las aldeas dependientes de Cazorla, solamente La Iruela pasó a ser villa ${ }^{3}$, aunque la existencia de esta comunidad fue la causa de frecuentes fricciones entre ambos concejos.

En una de sus estancias en el Adelantamiento de Cazorla, don Pedro Tenorio confirmó a La Iruela, 9 de septiembre de $1378^{4}$, su categoría de villa.

1 Agradezco al Dr. D. Alfonso Franco Silva, catedrático de Historia Medieval de la Universidad de Cádiz, su generosidad por facilitarme estas ordenanzas.

2 Quesada se constituyó como concejo principal del señorío jiennense de los arzobispos de Toledo, pero sus sucesivas pérdidas y conquistas, hasta su incorporación definitiva a los dominios cristianos en reinado de de Fernando IV, y su posterior donación a Úbeda por Alfonso XI, dio lugar a que Cazorla se convirtiera en la villa principal del Adelantamiento. J. de M. CARRIAZO: Colección Diplomática de Quesada, Jaén, 1975, LVII, LXXV y LXXXVI.

3 En el transcurso de la guerra entre Pedro I y Enrique de Trastámara, La Iruela pasó a ser villa por privilegio del arzobispo don Gómez Manrique, en recompensa a su fidelidad a su señor y al pretendiente al trono, pero posteriormente el privilegio sería derogado por el propio arzobispo. En 1378, don Pedro Tenorio devolvió a La Iruela su perdido privilegio. M. M. GARCÍA GUZMÁN: El Adelantamiento de Cazorla en la Baja Edad Media. Un señorío eclesiástico en la frontera castellana, Cádiz, 1985, 60-61.

4 M. M. GARCÍA GUZMÁN: El Adelantamiento..., 339-344. 
Pero en el privilegio arzobispal no hay ninguna referencia concreta a como se explotarían los términos comunes, por lo que fue necesario ir arbitrando una normativa, que quedó definitivamente establecida durante el pontificado del cardenal Cisneros. Este proceso fue largo, pues el margen de actuación del concejo de La Iruela era muy escaso al considerar a Cazorla "señora" del término. A lo largo de un siglo, hasta llegar a la concordia de 1497, se fueron adoptando diferentes acuerdos, algunos de ellos recogidos en las Ordenanzas de 1552, para regular el aprovechamiento en común de sus términos:

El 13 de enero de $1414^{5}$, don Pedro de Luna establecía diferentes espacios dentro del término, unos compartidos entre las dos villas y otros exclusivos de La Iruela. Entre estos últimos, se menciona expresamente la dehesa boyal de la villa ${ }^{6}$ y los sitios $^{7}$, tierras de labor de los vecinos de La Iruela, aunque su vigilancia correspondía a los caballeros de la sierra de Cazorla, quedando estos autorizados, "quando algunos ganados de do aquellos que no deben entrar a paçer en los dichos sytios,... los puedan prender o prendan por las penas acostunbradas." 8 . El resto de los términos, "en raçon del pasçer e cortar e caçar e pescar..."9, serían aprovechados por los vecinos de ambas villas.

En el mismo documento de don Pedro de Luna se hace referencia a que el concejo de Cazorla fijaba los periodos de veda, "porque en el tienpo que la dicha caza nasçe e se cria no sea estruida, so çiertas penas que ponedes contra cada uno de los que cazaren."10, pero sin contar con las autoridades

5 M. M. GARCÍA GUZMÁN: Colección Diplomática del Adelantamiento de Cazorla (12311495), Cádiz, 1991, 113-115. En 1473, a petición del concejo de La Iruela, don Alfonso Carrillo le autorizaba a promulgar una ordenanza para regular la explotación de la dehesa. L. POLAINO ORTEGA: Estudios históricos sobre el Adelantamiento de Cazorla, Jaén, 1967, 301-302.

6 La dehesa boyal fue asignada a La Iruela, el 5 de febrero de 1322, por Domingo Alonso, procurador del arzobispo de Toledo don Juan de Aragón, esta abarcaría desde "el çerro de la carrasca de Domingo Molina hasta el atalaya del puerto Cabrera, como va el rio Monrriel hasta las Çafurdas, e hasta el Espinosa, como da el camino de Bronchel e salle del camino de la fuente de Sigura.”. M. M. GARCÍA GUZMÁN: Colección Diplomática..., 19.

7 En la documentación del siglo XV y XVI, el término sitios designa a los lugares donde se concentraban las huertas, viñedos, olivares y otras plantaciones. C. ARGENTE DEL CASTILLO: La ganadería medieval andaluza. Siglos XIII-XVI. (Reinos de Jaén y Córdoba), Jaén, 1991, 36.

8 M. M. GARCÍA GUZMÁN: Colección Diplomática ..,114.

9 Ibídem.

10 Ibídem. La caza era uno de los aprovechamientos de montes y sierras. De ahí, que la normativa reguladora de esta actividad aparezca recogida en numerosas ordenanzas municipales. M. A. LADERO QUESADA: "La caza en la legislación municipal. Siglos XIII a XVIII", en La España Medieval. Estudios dedicados al profesor don Julio González González, Madrid, I (1980), 193-221. 
del concejo vecino. Para evitar diferencias, el arzobispo ordenó que tres o cuatro vecinos de La Iruela, designados por su concejo, participasen, junto con los oficiales de Cazorla, en la elaboración de las ordenanzas de caza, de cumplimiento obligatorio en ambas villas, incluso si La Iruela no enviaba a sus representantes ${ }^{11}$.

Durante el pontificado de don Alfonso Carrillo se da un importante paso en la regulación de las relaciones entre las dos villas, porque al ordenar, invariablemente, sus antecesores que se guardase la costumbre, se mantenía una estricta dependencia de La Iruela con respecto a Cazorla. Así, en junio de $1478^{12}$, don Alfonso Carrillo estableció que del total de los beneficios derivados de la explotación de los términos, un cuarto pertenecería a La Iruela, aunque en ningún momento se hace referencia a que los oficiales de este concejo pudiesen intervenir en su gestión; es más, en un primer momento el prelado había concedido a La Iruela la facultad de elegir a uno de los cuatro caballeros de la sierra, pero ante las protestas de Cazorla optó por anular la disposición.

Los acuerdos definitivos llegaron en 1497 y en ellos aparecen, por primera vez, referencias concretas a la Sierra de Cazorla. Los oficiales de ambos concejos concertaron una concordia ${ }^{13}$ en la que se detalla minuciosamente la explotación de los términos y el reparto de los beneficios. Los aspectos más importantes son los siguientes: se mantiene la utilización conjunta del término y se reconoce la preeminencia de la villa de Cazorla, "como señora del termino...", que se refleja en la forma de repartir los beneficios económicos, prestándose gran atención al aprovechamiento de los recursos de la Sierra de Cazorla. Así, todos los años, el último día de Pascua, los concejos de Cazorla y La Iruela nombrarían, respectivamente, cinco y tres representantes, que "sean tales personas que sepan la Sierra y termino.... y que estos que fueren diputados no sean señores de ganado...", su misión consistía en calcular el número de cabezas de ganado que podrían herbajar, teniendo en cuenta las condiciones de los pastos y que los ganados de los vecinos de ambas villas tenían preferencia sobre los extranjeros.

11 El 4 de enero de 1417, don Sancho de Rojas, confirmaba el documento de don Pedro de Luna sin introducir ninguna modificación a la normativa establecida por su predecesor. Ibídem, 132.

12 Ibídem, 345-347.

13 La reunión de los oficiales de los concejos de Cazorla y La Iruela se celebró en Cazorla, el 13 de agosto de 1497. Archivo Histórico Nacional (A.H.N.), Consejos Suprimidos, leg. 41.695 y Archivo Catedral de Toledo (A.C.T.), Obra y Fábrica, ms. 915, fols. 928r.-932v. 
Una vez establecido el número de cabezas de ganado, el concejo de Cazorla era el encargado de controlar su entrada y de percibir los impuestos. Según la concordia, a esta villa le correspondería íntegro el herbaje de 5.000 cabezas, porque esta renta era uno de los bienes de propios del concejo ${ }^{14}$. A partir de esa cantidad, La Iruela percibiría la cuarta parte de los beneficios, generados por la explotación de los pastos de la Sierra.

Esta misma proporción se mantiene "en todos los otros provechos que en los dichos terminos aya, ansy en cortas de pinos como de otras maderas, como en pasajes, como en otras qualesquier cosas, eçebto en los propios de la dicha villa de Caçorla.".

Por último, se reconocía al concejo de Cazorla la facultad de promulgar ordenanzas para regular la explotación de sus términos, pero tenía la obligación de comunicarlas al concejo de La Iruela, pues afectaba a los vecinos de ambas villas.

La concordia fue ratificada por el cardenal Cisneros el 30 de agosto de 149715 .

Estos acuerdos tuvieron vigencia en los años siguientes: en 1506 entraron a herbajar en la Sierra 19.907 ovejas, percibiéndose 5,5 maravedíes por cabeza, en concepto de herbaje, lo que arrojó un total de 109.488,5 maravedíes; de estos correspondieron a La Iruela 81.988,50, según lo establecido en la concordia ${ }^{16}$. Pero, a tenor de los datos conocidos, en los años siguientes iría aumentado progresivamente la entrada de ganados, así en 1513 se contabilizaron 61.340 animales ${ }^{17}$, llegando hasta 71.244 al año siguiente ${ }^{18}$. A estas cifras habría que añadir los ganados de los vecinos de Cazorla y La Iruela que tenían preferencia a la hora de utilizar los pastos de la Sierra.

Además de los pastos, la Sierra de Cazorla ofrecía otros recursos naturales, como es la madera, pero, curiosamente, de esta importante fuente de riqueza a penas hay referencias en la documentación. Desde la creación de La Iruela

14 El herbaje constituyó una renta saneada en el Adelantamiento, por lo que fue reclamada por el adelantado García de Villarroel ante el tribunal arzobispal. El 1 de abril de 1509, el adelantado y el concejo de Cazorla llegaron a un acuerdo en el reparto del herbaje. M. M. GARCÍA GUZMÁN: El Adelantamiento..., 301-302.

15 A.H.N, Consejos Suprimidos, 41.965 y A.C.T., Obra y Fábrica, ms. 915, fols. 932.-933r.

16 M. M. GARCÍA GUZMÁN: El Adelantamiento de Cazorla..., 301.

17 A.C.T., Obra y Fábrica, ms. 915, fol. 245r.-246v.

18 M. M. GARCÍA GUZMÁN: El Adelantamiento..., 301. 
como villa independiente, los vecinos de ambas villas podían cortar madera, destinada al autoabastecimiento: construcción de casas y cobertizos para los ganados, útiles agrícolas, carbón, combustible... Pero en la concordia de 1497, se incluye la explotación maderera como otra fuente de ingresos de los concejos: "Que en todos los otros provechos que en los dichos terminos aya, ansy en cortas de pinos, como de otras maderas... que la dicha villa d'El Yruela aya y lleve su quarta parte."19. Esto parece indicar que el concejo de Cazorla regulaba y explotaba la madera de su Sierra, pero no se ha conservado ningún documento, ni concejil ni señorial ${ }^{20}$, en el que aparezca tratado este aspecto. No obstante, existen datos que lo pueden ratificar: la cercana Sierra de Segura abastecía de madera, especialmente de pino, a toda Andalucía y su explotación correspondía al concejo de Segura de la Sierra ${ }^{21}$, regulándose esta actividad en unas ordenanzas. En 1492, Los Reyes, para evitar conflictos con los dueños de molino, aceñas y batanes, regularon el paso de "piaras de mill pinos" 22 , por el Guadalquivir y Guadalimar, este documento no especifica de donde procedían los pinos, pero teniendo en cuenta la cercanía y la semejanza entre la Sierra de Segura y de Cazorla, todo parece indicar que la madera que bajaba por el Guadalquivir procedía de estas Sierras. Por otro lado, las Ordenanzas de 1552 se centran, básicamente, en la protección y conservación de la masa forestal de la Sierra de Cazorla lo que puede ser indicio de que con anterioridad se produjo una sobreexplotación, planteándose ya en el siglo XVI el problema de la deforestación ${ }^{23}$.

19 A. C. T., Obra y Fábrica, ms. 915, fols. 928r.-932v.

20 En los escasos cuadernillos de cuentas conservados, pertenecientes al concejo de Cazorla o a los adelantados, no hay referencias a ingresos percibidos por la explotación de la madera de la Sierra de Cazorla.

21 J. RODRÍGUEZ MOLINA: El Reino de Jaén en la Baja Edad Media. Aspectos demográficos y económicos, Granada, 1978, 196-197. Entre las rentas percibidas por la Orden de Santiago en la encomienda de Segura se encuentran los derechos de las explotaciones madereras. M. A. LADERO QUESADA: "La Orden de Santiago en Andalucía. Bienes, rentas y vasallos a finales del siglo XV", en Los señores de Andalucía. Investigaciones sobre nobles y señoríos en los siglos XIII a XV, Cádiz, 1998, 539 y 560.

22 La provisión real está dirigida a los concejos de Córdoba, Jaén, Úbeda, Baeza, Andújar, Adelantamiento de Cazorla, encomienda de Segura y a los dueños de aceñas, molinos y batanes, situados en el Guadalimar y Guadalquivir. M. M. GARCÍA GUZMAN: Colección Diplomática..., 422427. Sobre el tráfico de madera de las Sierras de Segura y Cazorla véase, J. C. LÓPEZ ALMANSA: "El transporte de madera por el Guadalquivir", en Guad-el-Kebir, 59 (1999), 127-129.

23 La preocupación de la Corona por la conservación de la riqueza forestal se refleja en las pragmáticas reales de 1512 y 1518. M. A. LADERO QUESADA: Andalucía a fines de la Edad Media, Cádiz, 1999, 42. 
Otro factor que agravó esta situación fue la fuerte demanda de tierras de labor, al coincidir el aumento demográfico y la desaparición de la frontera con el Reino de Granada. Estas circunstancias favorecieron, desde principios del siglo XVI, un aumento considerable de las rozas.

En todo el Adelantamiento de Cazorla se mantenía vigente la antigua normativa foral que permitía a los vecinos del señorío rozar tierras para su puesta en cultivo, adquiriendo la plena propiedad sobre estas ${ }^{24}$, prueba de ello es que fue utilizada, en 1514, por el concejo de Cazorla para presentar una demanda contra el adelantado don García de Villarroel, porque "la dicha villa de Caçorla e vezinos della tienen por uso e costunbre e posesion paçifica, sin cotradiçion ninguna, de un año e de dos e de tres e çinco e diez e veinte $e$ treinta ... a esta parte e de tanto tienpo que memoria de honbres no es en contrario, que los vezinos de la dicha villa que sacaron montes e sotos e prados que despues sacados queda por suyo propio de la persona o personas que lo saca, por manera que muchos vezinos de la dicha villa de Caçorla de mucho tienpo acá lo acostunbran ansi hazer, han fecho e an sacado muchos montes e fecholos tierra rasa donde sienbran pan..." 25 . La vigencia de esta normativa se utilizó para hacer frente a la demanda de tierras de labor en el señorío, durante buena parte del siglo XVI, aunque en muchas ocasiones sirvió para encubrir apropiaciones ilegales. Por ejemplo, entre el 26 de septiembre y el 24 de octubre de 1513, el procurador del concejo de Cazorla, Diego de Alcaraz, demandó a cuatro vecinos por apropiarse de tierras del concejo $^{26}$. En otros casos eran la tierras de la mesa arzobispal, las que se veían afectadas por este problema; en una sentencia del corregidor de Cazorla, Alejo Calderón se describe con detalle como se realizaban: "algunos vezino de la dicha villa e d'El Yruela, con intençion de defraudar los derechos de la Santa Yglesia de Toledo e de los adelantados, en su nonbre, toman e ocupan de la dichas tierras rasas, la parte que dellas puedan tomar e ocupar, e las juntan con alguna poca cantidad de monte e lo roçan, e so color de la roça

24 En una claúsula del fuero de Quesada se especifica que: "De rroturas. Rotura que de nuebo fizier qualquier, y foras de exido o de rraiz agena la fizier, firme la aya y vala". J. de M. CARRIAZO: Colección Diplomática de Quesada..., 8-9.Todas las villas del Adelantamiento de Cazorla se repoblaron a fuero de Cuenca.

25 La demanda fue presentada, el 24 de julio de 1514, por García Ortiz, vecino de Cazorla, ante el corregidor de Cazorla Alejo Calderón. A. C. T., Obra y Fábrica, ms. 915, fols. 717v.-718v.

26 Las apropiaciones se realizaron en la dehesa del Cerro de la Cruz, en el ejido de la villa y en el pago de los Olivarejos. En todos los casos, las propiedades de los demandados lindaban con las tierras concejiles, lo que facilitaba su puesta en cultivo. A. C. T., Obra y Fábrica, ms. 915, fols. 670r.-672r. Y 709r.-709v. 
poça que hazen, aplican asi mucha parte de las dichas tierras rasas no pagando dellas terradgo..." 27.

De los años siguientes hay referencias a otras formas de explotación de los términos. La primera de ellas data de 1519, el 17 de marzo el concejo de Cazorla acordó "que se repartan los montes del Turmal, entre los cavalleros contiosos y otras personas, vezinos desta villa, que no tuvieren arreturas en el termino, sacadas por ellos ..."28. En 1528, el concejo de Cazorla trató "sobre razon de cierto monte que tiene tomado en los Portillos, de cabe la dehesa de las Salinas, Alonso de Torres", acordándose que el gobernador del Adelantamiento y un miembro del cabildo, "vayan... y lo vean y por donde les paresçiere que sea, sin perjuizio de la dehesa de las Salinas, le manden amojonar y señalar el dicho monte, para que asi señalado el concejo le de titulo dello..."29. Al año siguiente, en la reunión del cabildo se acuerda mantener los mojones establecidos por Juan Alonso de Caravaca, alcalde, y Francisco Godínez, jurado, en el pleito "questava de çierto monte entre Pedro Martínez e Christoval Martinez, su hermano, con Pedro Moreno."30. Estas escuetas noticias 31 no permiten establecer con exactitud las posibles obligaciones que tendrían los beneficiarios de estos repartimientos, ni los derechos que adquirían sobre estas parcelas de monte, ni como se explotaban, solamente se detalla con precisión, la única limitación que se impone para participar en reparto, ser propietario de tierras roturadas en los montes, medida encaminada, posiblemente, a evitar la inclusión de parcelas de monte en las rozas.

Estos datos inducen a pensar que en los primeros decenios del siglo XVI, se produjo un aprovechamiento poco controlado de la Sierra de Cazorla, por lo que fue necesaria una mayor intervención, tanto de las autoridades concejiles como de la propia autoridad señorial. En este sentido, es muy significativa una carta del concejo de Cazorla, fechada en 1527, en ella se

27 En esta sentencia, pronunciada el 24 de julio de 1514, el corregidor ratifica el amojonamiento de las tierras pertenecientes a la mesa arzobispal, realizado por el adelantado García de Villarroel, para poner fin a estas prácticas fraudulentas. A. C. T., Obra y Fábrica, ms. 915, fols. 717v.-718v.

28 A. C. T., Obra y Fábrica, ms. 915, fol. 737v.

29 A. C. T., Obra y Fábrica, ms. 915, fol. 311v.

30 A. C. T., Obra y Fábrica, ms. 915, fol. 315v.

31 Los fondos medievales del archivo municipal de Cazorla no han llegado hasta nuestros días, pero con motivo del pleito entre la Iglesia de Toledo y el marqués de Camarasa, adelantado perpetuo de Cazorla, se hicieron numerosos traslados de documentos, entre estos se encuentran algunas actas del cabildo de Cazorla. 
expone al arzobispo de Toledo, don Alfonso de Fonseca, entre otros asuntos la explotación de la Sierra de la villa: "Ytem por quanto esta villa de Caçorla tiene una sierra donde hervajan los vezinos sus ganados y donde el conçejo desta villa tiene sus propios e rentas de los ganados estranjeros, que en ella hervajan, y algunos vezinos desta villa de Caçorla y d'El Yruela, asi clerigos como legos, de hecho e si lo poder hazer se an entrado y entran en la dicha sierra a la talar, arar y ronper en ella, en tal manera que destruyen los pastos e cortan e destruyen los enzinares e robredales della e otros arboles de fruto de que viene mucho daño e perjuyzio a esta dicha villa e vasallos e a sus propios e rentas. Que se suplica a su señoria reverendisima de que ningun clerigo ni lego destas dichas villas sea osado de arronper, talar, ni arar en la dicha Sierra."32.

De se mismo año data un mandamiento del concejo de Cazorla, en él que se ordena a Juan Barroso, alguacil de la Hermandad de la villa, que con la gente necesaria fuese a la Sierra y prendiese a los vecinos de la villa y de La Iruela que "hallaredes arando e arronpiendo con que no sea en el Canpillo y en los Almigranes."33. En el mismo documento se establece que los infractores serían castigados, según las penas establecidas en las ordenanzas, hechas públicas mediante pregón.

La situación expuesta en los documentos, muestra que, conforme fue transcurriendo el siglo XVI, el concejo de Cazorla tuvo que establecer una normativa en la que se regulaba, de manera más restrictiva, la explotación de la Sierra, limitando la tala de árboles ${ }^{34}$, entrada de ganados $\mathrm{y}$, sobre todo, prohibiendo las rozas.

32 Ibídem, fols.301r.-303v.

33 El mandamiento esta hecho en Cazorla, el 16 de mayo de 1527, en él se informa al alguacil de la Hermandad que las rozas se habían hecho en Poyo Manquillo, Poyo Sentil y la cañada de medio. A. C. T., Obra y Fábrica, ms. 195, fols. 921v.-922r.

34 Los vecinos de Cazorla y La Iruela podían cortar la madera que necesitasen para sus útiles agrícolas, pero haciendo uso de este derecho cortaban grandes cantidades de madera, que luego vendían fuera de la villa. Esta práctica fue prohibida por el concejo de Cazorla, 30 de octubre de 1531, bajo pena de 600 maravedís. A. C. T., Obra y Fábrica, ms. 195, fols. 751v. 


\section{LAS ORDENANZAS DE 1552}

Estas Ordenanzas ${ }^{35}$ tienen como objetivo principal regular la explotación de la Sierra de Cazorla y con carácter muy secundario se hace referencia a otros espacios del término de la villa, como dehesas, ejidos, heredades., lo que puede ser indicio de la existencia de unas ordenanzas mas amplias, recopilándose en éstas solo los aspectos relacionados con los aprovechamientos forestales. La normativa aparece recogida en diecisiete puntos y a través de ellos se detalla como utilizar los recursos naturales de la Sierra, pero su explotación debía de estar siempre subordinada a la conservación y protección de su masa arbórea, con el fin de preservar su riqueza principal que es la madera.

Por otro lado, las Ordenanzas de 1552 recogen las iniciativas tomada por el concejo de Cazorla, a lo largo del siglo XVI, y cuya finalidad era acabar con prácticas abusivas, generalmente, relacionadas con la tala de árboles 0 con la entrada de ganados en la Sierra ${ }^{36}$. La madera, debido a sus múltiples utilidades, se constituye como una materia de primera necesidad, pero, a mediados del siglo XVI, la deforestación ${ }^{37}$ era un hecho en algunas regiones de la Península y de ahí la intervención de la Corona ${ }^{38}$, regulando la

35 La bibliografía sobre ordenanzas municipales es muy numerosa, véase: M. A. LADERO QUESADA y I. GALÁN: "Las ordenanzas locales en la Corona de Castilla como fuente histórica y tema de investigación (siglos XIII al XVIII)", en Anales de la Universidad de Alicante. Historia Medieval, 1 (1982), 221-243. A. FRANCO SILVA: Estudios sobre Ordenanzas Municipales (Siglos $X I V-X V I)$, Cádiz, 1998. P. A. PORRAS ARBOLEDAS: "Las ordenanzas municipales. Algunas propuestas para su estudio y un ejemplo", en Espacio, Tiempo y Forma, serie III, Historia Medieval, 7 (1994), 49-64. Ordenanzas de la Muy Noble, Famosa y Muy Leal ciudad de Jaén, guarda y defendimiento de los reinos de Castilla, Granada, 1993. "Fueros, privilegios y ordenanzas de la villa de Jódar. Cinco siglos de derecho municipal”, en Historia, Instituciones y Documentos, 21 (1994), 391422. C. ARGENTE DEL CASTILLO y J. RODRÍGUEZ MOLINA: "La ciudad de Baeza a través de sus ordenanzas", En la España Medieval, 10 (1987), 323-342.

36 El 30 de octubre de 1531, el concejo de Cazorla, además de prohibir la venta de madera fuera de la villa, estableció que para pedir la vecindad era necesario tener casa abierta y con la familia establecida en Cazorla. Con esta medida se trataba de evitar que los ganaderos se avecindasen temporalmente en la villa, para hacer uso del derecho de sus vecinos a meter libremente sus ganados en la Sierra de Cazorla. A. C. T., Obra y Fábrica, ms. 195, fols. 751r.

37 Diversas instituciones, entre ellas la Corona, adoptaron medidas repobladoras para hacer frente a este problema. Así, los pinares situados al sur del Duero se deben a las iniciativas de Felipe II y sus sucesores. A. DOMÍNGUEZ ORTIZ: El Antiguo Régimen: Los Reyes Católicos y los Austrias, en Historia de España, dirigida por M. Artola, Madrid, 1996, 206.

38 Como ocurre en las Ordenanzas de Cazorla, en las de Jaén, en el título VI, dedicado a sierras y montes y, concretamente, en la ordenanza XIII, se hace referencia a una ejecutoria real, en la que se regula la conservación de los montes de la ciudad. La ordenanza está fechada en 1549. P. A. PORRAS ARBOLEDAS: Ordenanzas de la muy noble..., 130. 
explotación de sierras y montes y facultando a los concejos para promulgar nuevas ordenanzas, en las que se primase la necesidad de proteger la masa arbórea de sus términos. En el caso de Cazorla, la normativa de 1552, acaba con la antigua costumbre de las rozas en la Sierra, imponiéndose la pena de 600 maravedíes por cada árbol cortado o arrancado, además de la contenida en la provisión real. Pero, salvo en aspectos muy concretos como este, en general, se trata de compaginar los derechos de los vecinos de Cazorla y La Iruela a explotar sus montes con la conservación de los mismos.

En las Ordenanzas aparecen las principales especies arbóreas que poblaban la Sierra de Cazorla, robles, pinos, encinas, carrascas, chaparros y quejigos. Su tala solo podría ser autorizada por el concejo de Cazorla, pero las propias autoridades municipales, conscientes de las frecuentes irregularidades, establecieron que solo serian válidas las licencias concedidas en las sesiones del cabildo. Cualquier corta, realizada sin la preceptiva autorización, sería penalizada con 600 maravedíes por cada árbol mayor, o con 300 en el caso de chaparros o quejigos, prestando las ordenanzas especial atención a la protección de los pinos, principal riqueza forestal de la Sierra de Cazorla, castigándose con 600 maravedíes la tala de cualquiera de sus variedades. El doble de estas penas serían pagadas por los miembros del cabildo que concediesen licencias fuera de las reuniones del concejo.

Entre las disposiciones recogidas en estas Ordenanzas, tienen especial interés las relacionadas con la explotación y comercialización de la madera. En principio, estas actividades podrían ser desarrolladas por cualquier persona, siempre que contase con la preceptiva licencia del concejo de Cazorla, aunque no fuese vecino de las villas ${ }^{39}$. Pero quedaba prohibido sacarla, labrada o sin labrar, fuera de los términos de Cazorla y La Iruela, bajo de pena de 600 maravedíes por carga, más la pérdida de la madera, sino se contaba con la autorización de las autoridades municipales. Esta norma

39 Las autoridades concejiles, además de conceder las licencias, establecían los meses del año, en los que se podían talar los árboles. En las Ordenanzas de Jaén se explica con precisión la importancia de este aspecto: "por quanto el cortar de la madera fuera de tiempo muchas obras se pierden porque la madera se carcome toda y queda la obra perdida ... que ningunas ni algunas personas de qualquier estado e condicion que sean ... no sean osados de cortar ... salvo los meses de setiembre y octubre y noviembre y diziembre". P. A. PORRAS ARBOLEDAS: Ordenanzas de la muy noble..., 128-129. La explotación y comercialización de la madera de la Sierra de Segura estuvo controlada por vecinos de Úbeda, hasta que mercaderes sevillanos obtuvieron concesiones del concejo de Segura, dando lugar a un pleito fechado hacia 1565. J. RODRÍGUEZ MOLINA: El Reino de Jaén, en Historia de Andalucía, dirigida por A. Domínguez Ortiz, vol. IV, 157. 
restringía, en gran medida, la comercialización de la madera, pero se ajusta perfectamente al fin buscado por estas Ordenanzas, la explotación racional de los recursos naturales de la Sierra de Cazorla, compatible con la conservación de su importante masa arbórea.

Entre los aprovechamientos contemplados aparece la elaboración de carbón, aunque se impone una nueva normativa, para evitar las talas excesivas. Todos los años, en el segundo cabildo, celebrado después del día de San Miguel, se designarían a dos de sus miembros que serían los encargados de señalar a los carboneros el lugar de la Sierra, donde realizarían su trabajo y los árboles que podrían cortar. El incumplimiento de esta norma se castigaba con las mismas penas en que incurrían los que cortaban árboles sin licencia del cabildo.

Igualmente, se mantiene a los vecinos de ambas villas el derecho a cortar madera, previa autorización del concejo de Cazorla, para "las labores de sus casas y edifiçios", pero se prohíbe la antigua costumbre de pagar con madera al leñador, cuyo el salario solo podría satisfacerse en dinero. La infracción de esta disposición se penalizaba con 600 maravedíes, afectando tanto al vecino como al leñador, quien además perdía la madera recibida como salario. Para el caso especifico de los pinos, la multa se elevada hasta los 2.000 maravedíes.

La escasez de tierras de labor da lugar a que las actividades agrícolas tengan un trato de preferencia en las Ordenanzas, permitiendo a los labradores de Cazorla y La Iruela unas posibilidades más amplias en el aprovechamiento de su Sierra. Así, podían cortar, en cualquier época del año, la madera que necesiten para sus aperos de labranza y construcción de tinadas y chozas; aunque "por creçimiento de la jente, los arboles apropiados para havios y arados se van acabando", se les prohíbe sacar madera, sin licencia del cabildo, para su comercialización fuera del término de las villas, so pena de 600 maravedíes. Asimismo, en épocas de sequía y ante la escasez de pastos, los ganados de labor "puedan ramonear en la dicha syerra, dexando horca y pendon..."40.

Por último, las Ordenanzas contemplan la explotación ganadera de la Sierra, pero condicionada a la protección de la masa arbórea, por lo que se

40 Disposiciones semejantes se encuentran en las Ordenanzas de la villa de Belalcázar e Hinojosa. M. C. ARGENTE DEL CASTILLO: La ganadería medieval andaluza..., 378. 
establece una estricta normativa que afecta tanto a los pastores como a sus rebaños y, sobre todo, se limita de manera muy significativa la entrada de ganados extranjeros a herbajar. Así, los pastores podían cortar ramas de cualquier árbol para hacer fuego y construir chozas y corralizas, siempre que no encontrasen madera cortada o seca en los alrededores, 100 pasos, pero les estaba prohibido cortar árboles por el pie, infracción sancionada con 600 o 300 maravedíes, según la variedad de árbol. Los ganados podían aprovechar las hojas y brotes de los árboles, pero el ramoneo estaba prohibido si los árboles tenían fruto; además, si se cortaban ramas, era siempre obligatorio dejar horca y pendón, según la costumbre. Desde San Miguel hasta San Lucas quedaba prohibido varear los árboles, bajo pena de 2.000 maravedíes que aumentaría en 600 maravedíes más, si se encontraba al pastor vareando, pasado este plazo se podían recolectar los frutos, especialmente las bellotas. Estas disposiciones afectaban tanto a los vecinos de las villas como a los dueños de ganado que arrendaban los pastos de la Sierra. En 1552, según se recoge en las ordenanzas, el concejo de Cazorla los había arrendado a Pedro Chenos, aunque el número de cabezas de ganado se había reducido a 25.000, cifra muy inferior a las de años anteriores, los ganados estarían en la Sierra desde el 25 de mayo hasta el 29 de septiembre. El herbaje quedó establecido en 10 maravedíes por cabeza.

Las Ordenanzas recogen unas disposiciones especificas para el ganado porcino, limitando su presencia en la Sierra de Cazorla, a pesar de que un importante sector de la población obtenía del cerdo la principal fuente de grasa y proteínas: En primer lugar estaba prohibido criar a estos animales en la Sierra, a pesar de ser un uso pastoril de gran tradición en la zona ${ }^{41}$, castigándose con 600 maravedíes y la pérdida de los animales; solamente podrían subir a partir del día de San Miguel, bajo pena de 2.000 maravedíes por manada, más de doce cerdos, o dos reales por animal. Les está prohibido ramonear en el tiempo que le está permitido a los otros ganados, en caso de hacerlo el guarda se vería sujeto a las penas en las que incurren los que cortan árboles. La normativa especifica para el ganado porcino se debe, según las Ordenanzas, "porque en el monte y parte de syerra que se paran lo secan todo".

En la misma línea de protección, se prohíben algunas prácticas usuales, pero muy perjudiciales para los árboles, como era la de rociar los ramas y

41 Ibídem, 122-124. 
matas con sal, para que el ganado lo rozase. La infracción suponía la perdida del ganado más una multa de 600 maravedíes.

Por último, las Ordenanzas no solo adoptan medidas sancionadoras, encaminadas a proteger las especies arbóreas de su Sierra, sino que contemplan otras repobladoras, "porque los terminos desta villa sean mas hornados e aya mas arvoles para pastos y abrevaderos, damos licencia e facultad a todos los vezinos de estas villas para que puedan plantar qualesquier arboles ... e sean suyos propios los arboles..., con quel pasto donde se plantaren los dichos arvoles ... quede libre para los vezinos y moradores desta villa y concejo della".

\section{ORDENANZAS DE CAZORLA.}

Archivo de la Casa Ducal de Alburquerque. Cuéllar, $n^{\circ} 213$, leg. 1, $n^{\circ} 22$.

Yo Francisco de Caçorla, escrivano de sus majestades y del numero desta villa de Caçorla, doy fee a los señores que la presente vyeren que el conçejo, justicia y regimiento de esta villa de Caçorla en su archivo tiene las hordenanças que de yuso se haran mençion, en lo que toca a la sierra y terminos desta dicha villa y las hesecuta y lleva las penas en ella contenidas a las personas que en ellas caen e yncurren, las quales hordenanças saque del original y son las siguientes:

Primeramente que por quanto por esecutoria y provision real de su majestad, atenta la utilidad de los dichos montes y la nesidad que dellos ay y que sean conserbados, esta mandado que nyngun vecino desta villa ny de fuera parte pueda arronper, arar, ny panyficar en la dicha syerra del tienpo contenido en la dicha executoria, queremos que la dicha executoria se guarde en todo y por todo como en ella se contiene y la pena en ella contenida sea cunplida y executada y porque mejor se execute, mandamos que qualquier que ronpiere y arare en la dicha sierra por qualquiera çepa que sacare e arbol que cortare, demas de las penas en la dicha executoria contenidas, por cada çepa que sacare o arbol que cortare page seyçientos maravedis de pena.

Otrosy conformandonos con la probisyion real de su majestad que qualquiera persona de qualquier calidad o condiçion que sea que cortare carrasca o robre o otro qualquier arbol mayor page de pena seysçientos maravedis y el que cortara chaparro o quexigo page trezientos maravedis. Con / que devemos declarar y declaramos quel pastor de ganado pueda cortar para 
cozer y para hazer corraliza y para quemar en el tienpo que lo tubiere neçesidad, lo que obiere menester para lo susodicho, con que se entienda que para cozer y quemar para el fuego, quando no se hallare en lugares donde para lo susodicho çien pasos alrededor donde estuviere, no obiere leña cortada o seca para el dicho efeto y para la dicha corraliza pueda cortar donde pusiere su majada de monte baxo e pueda ramonear, con tanto que dexe orca y pendon en el arbol que ramoneare, conforme a la antigua costunbre, y entendiendose que pueda ramonear en el tienpo que los arvoles no tuvieren fruto, so pena que por cada pie que cortare page, syendo de arvol mayor, seyçientos maravedis y por cada rama o chaparro trezientos maravedis, sygun de suso.

Otrosy hordenamos y mandamos que qualquier que cortare pyno chico o grande, travesaño o rollizo o de otra qualquier manera syn licencia y mandado de los señores del cabildo que son o fueren desta villa en el tienpo que por la dicha dicha justicia y regimiento les fuere señalado para cortar en la dicha syerra, por cada un pie que asy cortaren syn la dicha licencia page sysçientos maravedis de pena.

Otrosy que los labradores destas villas puedan cortar para todo jenero de sus labores y para teynadas y choças y aperos libremente en qualquier tienpo del año, syn que por ello caygan ny yncurran en pena alguna, / toda la madera que para lo susodicho obieren menester y lo mysmo se pueda cortar libremente para cabañas y choças de pastores y estançias de puercos.

Otrosy declaramos que los labradores y vezinos destas villas y boyarizos dellas en tienpo de neçesidad puedan ramonear la dicha syerra dexando horca y pendon, mas que no puedan cortar por pie ningun arbol, so las penas de susocontenidas, eçebto de arboles que no lleben fruto ninguno, con que la corta y ramoneo no sea cosa muy eçesiva.

Otrosy que los puercos desta villa no suban a la syerra della hasta el dia de San Miguel de setienbre de cada un año, so pena de dos mill maravedis por cada manada que a la dicha syerra subiere antes el dicho dia y entiendase ser manada de doze puercos arribas y hasta doze puercos page por cada un puerco de pena dos reales por cada vez que le hallaren dentro.

Otrosy mandamos que las personas que metieren puercos en la dicha syerra del dia de San Miguel adelante y hasta el dia de San Lucas del mes de otubre de cada un año para syenpre jamas, el pastor que los guardare o otra qualquier persona no puedan varear las enzinas, robres ni otro qualquier jenero de arboles de la dicha syerra, so pena de los dichos dos mill maravedis y puesto 
quel dicho pastor no se halle vareando, sy se hallare con vara page seyçientos maravedis de pena, por cada vez que con ella se hallare e caya e yncurra en la misma / pena. El que vareare con bordon o gancho o palo que truxere y con otra qualquier cosa que vareare en qualquier forma, via y manera que se le averiguare, con que devemos declarar y declaramos que en mysma pena caya e yncurra el pastor de ganado lanar o cabryo o de bacas que vareare los dichos arboles antes del dicho dia de San Lucas en la dicha Syerra en la forma susodicha.

Otrosy mandamos que los ganaderos, pastores y guardas de puercos no puedan cortar nyngun jenero de arboles por el pie ni ramonear en el tienpo que los pastores de ganado lo puedan hazer aunque dexen horca y pendon, so las penas en los capitulos antes deste contenidos que hablan çerca de los que cortan, talan y ramonean en la dicha syerra.

Otrosy porque por espirençia se a visto el daño que se a seguido e lo que se podia seguir de que las personas del cabildo, fuera de los dias de ayuntamiento e cabildo, dan licencia para cortar madera en la dicha syerra. Por ende ordenamos y mandamos que de aqui adelante, direte ni yndirete, no se pueda dar licencia para cortar madera en la dicha syerra, nynguna persona desta villa ni fuera parte, de qualquier calidad e condiçion que sea, syno fuere en los dias de cabildo y estando juntos la justicia y regimiento, haziendo cabildo, y sy contra lo susodicho se diere licencia sea en sy nynguno y el que lo cortare, por virtud de la tal licencia cayga e yncurra en las penas destas hordenanças, en que caen e yncurren las personas que cortan y talan syn licencia de la justicia y regimyento de suso en estos ca/pitulos declaradas y la persona o personas que fueren en dar la dicha liçençia fuera del dicho cabildo pagen la pena doblada.

Otrosy por quanto el deshorden que se a tenido en la manera de hazer el carbon en la dicha syerra por las personaas que destas villas tienen por costunbre de lo hazer a cabsado gran daño en la dicha syerra y se an hecho y hazen de cada dia grandes y eçesivas talas en los arboles della y por evitar lo susodicho y dando la horden que de aqui adelante se deva tener para que cesen los dichos daños e ynconvynientes. Hordenamos y mandamos que de aqui adelante las dichas personas que asy hazen el dicho carbon no lo puedan hazer en nynguna parte de la dicha syerra, salvo en lugar y parte que por el cabildo desta villa le fuere señalado en cada un año, el qual lugar y parte en que se haga el dicho carbon sea señalado por las personas del cabildo desta dicha villa a dos cabildos despues del dia de San Miguel de setiembre de cada un 
año para syenpre jamas, porque vayan dos personas del dicho cabildo a señaladar el dicho lugar y parte para hazer el dicho carbon y las personas que fueren asy a señalar el lugar donde se obiere de hazer el dicho carbon declaren a los carboneros los arvoles que an de dexar de que no puedan hazer carbon e la persona o personas que contra lo susodicho hizieren carbon, sea punido y castigado e caya e yncurra en las penas en que caen e yncurren los que talan e cortan en la dicha syerra syn licencia, conforme a estas dichas nuestras hordenanças.

Yten por quanto por espirençia se a visto el gran daño que en la dicha nuestra / sierra an hecho y hazen los señores de ganado que traen machos nudridos y cerdos, porque en el monte y parte de syerra que se paran lo secan todo. Y el mysmo daño se reçibe de los que con agua sal riegan los arbores y matas de la dicha syerra. Y por conserbar los dichos arvoles y syerra hordenamos y mandamos que nynguna persona ny señor de ganado, de qualquier condiçion y calidad que sea pueda criar ny traer en la dicha syerra nyngunos machos nudridos y cerdos, so pena de seyçientos maravedis y mas que aya perdido los dichos machos nudridos y cerdos y en la mysma pena caya e yncurra la persona que ruçiare con agua sal los arvoles y matas para que los ganados lo roçen.

Yten por quanto por creçimiento de la jente, los arboles apropiados para havios y arados se van acabando, hordenamos y mandamos que nynguna persona, de qualquier calidad e condiçion que sea, pueda sacar la dicha madera a la vender fuera destas villas syn licencia del cabildo, so pena de la aver perdido y mas seyçientos maravedis de pena.

Otrosy por quanto por espirençia se a visto el daño que se a seguido e sige de que a las personas a quien se da licencia para cortar madera en la dicha syerra para las labores de sus casas y edifiçios, dan la meytad de la madera que se les da a las personas que se la cortan y asyerran y asy se corta doblada madera de lo que an menester para los edifiçios y labores de sus casas. Por ende hordenamos y mandamos que de aqui adelante nynguna / persona de qualquier calidad e condiçion que sea a quien se diere licencia para cortar y aserrar pinos para los edifiçios y labores de sus casas y en otra qualquier manera de la madera que asy se le diere licencia que corte, al que se la cortare o aserrare no le pueda dar parte de la dicha madera, salvo que le page su trabaxo del cortar y aserrar en dineros, sygun se conçertare, so pena que la persona que tuviere licencia para cortar la dicha madera y diere parte della al que se la cortare e aserrare caya e yncurra en pena de seyçientos maravedis 
por cada arvol o parte del que diere al cortador e aserrador y en la mysma pena aya e incurra el cortador o aserrador que reçibiere la dicha mandera e mas la aya perdido.

Otrosy hordenamos y mandamos por los grandes daños e ynconvinientes que se an seguido y sygen no puedan sacar nin saquen de la dicha syerra ni destas dichas villas ninguna persona dellas ni de fuera parte ninguna madera labrada ni por labrar, so pena que por cada carga que sacare labrada o por labrar se page seysçientos maravedis de pena y la madera pierda, esto syn licencia del cabildo.

Yten que ninguna personas destas villas ni de fuera parte pueda cortar arbol nynguno ni sacar çepa de las dehesas desta villa, so pena de seyçientos maravedis por cada arbol o çepa que sacaren y de la dehesa nueva, so la dicha pena ninguna leña ni rama sino fuere vega para los labradores, con que no corten por alto, syno fuere por el pie de monte baxo.

Otrosy porque los terminos desta villa sean mas honrados e aya mas arvoles para pastos y abrevaderos damos licencia e facultad a todos los vezinos de estas villas para que puedan plantar qualesquier arboles que quisieren e por bien tuvieren en los exidos e publico conçegil e sean suyos propios los arboles que asy plantaren, con quel pasto donde se plantaren los dichos arvoles de qualquier jenero que sean quede libre para los vezinos y moradores desta villa y concejo della.

Otrosy hordenamos y mandamos quel aserrador o aserradores a quien los vezinos destas villas dieren a serrar los pinos de que se les hiziere merçed para sus casas, edifiçios y labores, el tal pyno o pynos que asy aserraren por virtud de las dichas licencias y merçedes no pueda guardar ni apropiar para si parte alguna del tal pyno o pinos, salvo que que toda la madera que del tal pyno o pinos saliere se la den a la persona o personas a quien se hiziere la dicha merçed, so pena de quel aserrador o aserradores que para sy apropiaren o tomaren cosa alguna de los tales pynos cayga e yncurra en pena de dos mill maravedis aplicados sygun de suso.

Asy mismo doy fe que qualquiera buey o vaca o yegua e mula e asno que entra en heredad ajena, en panes o en otras heredades, paga de noche un real $\mathrm{y}$ de dia medio real.

Asy mismo de cada cabeça de puercos que entra en las cosas dichas paga la propia pena. 
Asi mismo de cada res menuda que entren en los dichos lugares pagan çinco maravedis cada cabeça.

Asy mismo de cada manda de ovejas que anda entre cargas paga seysçientos maravedis y asy mismo cabras.

Y los puercos que andan de noche en restrojos o fuera dellos pagan o fuera dellos pagan seysçientos maravedis de pena. Asy mismo ay sytios que se guardan desde Santiago fasta Todos Santos y los ganados que entran en ellos pagan de pena seysçientos maravedis.

La syerra desta villa se arrienda a Pedro Chenos y meten en ella veynte y çinco cabeças de ganado y pagan por cada cabeça diez maravedis y entran a veynte y çinco de mayo y salen por San Miguel e antes sy antes quysieren

En esta villa no ay cañadas ni a donde pasen por esta rason no va aqui hordenança dellas.

En testimonio de lo qual do esta, fecha en Caçorla en veynte e dos dias de setienbre de I U DLII años.

Porques verdad fiz aqui este mio sig(signo)no en testimonio fecho. Francisco de Caçorla, escrivano del cabildo y del numero. 